original papers

MARILYN A. EWAN AND RUSSELL J. GREENE

\title{
Provision of a community pharmacist-run medication advice service at mental health resource centres
}

A pilot study

\section{AIMS AND METHOD}

To assess what medication information long-term mentally ill patients required and acceptability of an advice service. Confidential consultations were offered by a community pharmacist at two mental health resource centres. The service was evaluated by patients and staff by questionnaire.

\section{RESULTS}

Data were collected on 33 consultations (30 users; three attended twice). Mean duration of consultations was 14.9 minutes (range 5-45). Antipsychotics and antidepressants were most commonly prescribed and enquired about. Most drug enquiries concerned adverse drug reactions $(n=24)$ and therapy choice $(n=17)$. All patients and staff hoped the service would be fully implemented.

\section{CLINICAL IMPLICATIONS}

Community pharmacists represent an acceptable, but underutilised, information provision service. Such a service could be overseen by specialist psychiatric pharmacists. This study reflects patients' concerns about the use of antipsychotics and antidepressants and the need to address them. Further work is needed to determine the impact of the service on clinical outcome.
Medication-related problems in the long-term mentally ill in the community can have far-reaching consequences. Research has shown that 'patients have far more opportunities to fail to take their medication, whether intentional or otherwise' if they are receiving medication for mental health problems outside the hospital setting (Donoghue, 1994). Two pilot studies on the contribution community pharmacists could make to the care of the long-term mentally ill (in Liverpool and Nottingham) have been reported (Donoghue, 1994; Nottinghamshire Family Health Services Authority, 1994; Aldridge et al, 1996; Watson, 1997). The Liverpool community pharmacists provided specialist dispensing (e.g. adherence aids, instalment dispensing) and information services (e.g. to patients, day centre staff and carers). All found the service useful because community pharmacists were "more approachable than general practitioners" and gave impartial advice (Donoghue, 1993). The UK Psychiatric Pharmacy Group (UKPPG) produced a consensus statement in 1995 on the needs of the long-term mentally ill and how community pharmacists' intervention would help (UKPPG, 1997), including education and reassurance of patients and carers. As the majority of such patients receive primary care treatment, we decided to assess the role of community pharmacists in mental health resource centres.

\section{The study}

The aims of this service were to:

(a) answer queries about medication;

(b) assess patient response to and acceptance of the service.

Two mental health resource centres participated. Patients experienced a wide range of mental illnesses. Both centres offered regular services such as counselling, drugs and alcohol support, and social and educational activities. The community pharmacist-run advice service neither offered an opportunity to discuss the doctor's choice of therapy, nor provided a 'Samaritans'-type counselling service. The community pharmacist aimed to offer confidential consultations in a friendly and independent manner. Where appropriate, patients were referred on to keyworkers, psychiatrists, specialist counselling services or telephone advice-lines. The service provided was free to both the patients and the resource centres. The community pharmacist received no remuneration for providing this pilot service. Sessions were held once a week for four consecutive weeks (duration 1-3 hours). Patients were seen on a first come, first served basis. A written record of each consultation was made, including patients' medication, adherence (self-reported), sideeffects experienced and advice given. Patients and staff were given anonymous self-completion service evaluation questionnaires, after each consultation and at the end of the four-week service, respectively.

\section{Findings}

There were 33 consultations (including repeat visits) and 30 patients; this included a pair of concerned parents. Seventeen (52\%) were female. The mean duration of the consultations was 14.9 minutes (range 5-45). Patients received a total of 72 prescribed drugs. Antipsychotics and antidepressants were the most common types of psychotropic medication received (18\% and 15\%, respectively). Non-psychotropic medication included: metereddose asthma inhalers; analgesics; hormone replacement therapy; multivitamins; cardiovascular medication; antidiabetic therapy; and anti-arthritic therapy. 
Table 1. Examples of adverse effects experienced and likely drugs, both as reported by users

\begin{tabular}{|ll}
\hline Adverse effects & Likely drugs \\
& \\
\hline $\begin{array}{l}\text { Sickness with } \\
\text { gastrointestinal }\end{array}$ & $\begin{array}{l}\text { (a) Chlorpromazine } \\
\text { upset }\end{array}$ \\
& $\begin{array}{l}\text { paroxetine, co-proxamol, keto- } \\
\text { profen, ibuprofen, zopiclone } \\
\text { and prochlorperazine }\end{array}$
\end{tabular}

No. of Comments Advice given

reports

2 profen, ibuprofen, zopiclone

Hypersalivation

(a) Risperidone

(b) Fluphenazine

2

Dry mouth

Weight gain

(a) Dothiepin and chlorpromazine
(b) Olanzapine

Tiredness
(a) Sulpiride
(b) Droperidol and lithium
(c) Fluphenazine (injection)
(d) Fluoxetine
(e) Fluoxetine and amitriptyline

(d) Patient receiving fluoxetine only did not know whether these were attributable to fluoxetine or stress.

Was also receiving droperidol, but attributed these adverse effects to lithium alone.

menstrual cycle and also stated "hair hurts"

Slurred speech and movement problems (shuffling) and very flexible limbs

Anxiety attacks and hair and weight loss and craving for sweet foods and nausea

Facial stiffness described as 'zombie-like' and blurred vision

Dizziness Fluoxetine

\section{Fluphenazine (injection)}

Fluoxetine and amitriptyline

Haloperidol (injection)
Patient drinks a lot of tea, not realising its dehydrating potential.
Also had paranoid delusions concerning people laughing at him and the sideeffects. Also receiving orphenadrine.

\section{Did not know} whether these were attributable to fluoxetine or stress.

Patient said he was taking procyclidine for this adverse effect.

(a) Take chlorpromazine with food (as patient complained of discomfort when taken on empty stomach). Also exercise, healthy eating to reduce constipation. (b) Take NSAIDs with food. Consult GP as to why taking 2 NSAIDs and to possibly reduce number of medicines.

(a) Recommended to speak to prescriber for a possible change from ineffective prescribed procyclidine to alternative, e.g., benzhexol.

(b) Prop-up pillow at night.

Drink plenty, suck boiled sweets, ice cubes or pineapple chunks. Reduce caffeine intake.

Both patients advised on healthy eating and given reassurance.

(a) Speak to keyworker or psychiatrist.

(b) See prescriber as may alter dose to night-time dose.

(c) Try and keep to a regular sleeping pattern to allow body to adjust. (d) Possibly take SSRI at night.

(e) Speak to prescriber about possibly taking higher doses at night and less during day.

'Unwind' before settling down at bedtime (e.g. read, hot milk). Talk to psychiatrist about perspiration. Watch diet, drink water or low calorie drinks. Drink when thirsty. Wait for results of medical tests regarding menstrual cycle. Speak to psychiatrist about 'hair hurting' to discuss what the problem really is. Speak to keyworker or psychiatrist.

Relaxation techniques. Healthy diet and advised weight loss is a result of reduced appetite caused by drug. Nausea wears off eventually - if not see prescriber.

As patient stopped medication and was no longer experiencing these effects, patient was simply reassured.

Speak to keyworker or prescriber if persists. 
Sixty per cent of patients experienced side-effects. Examples are listed in Table 1. Sixty per cent said they were adherent to their medication. Reasons given for poor adherence included: forgetfulness; fear of taking or initiating treatment; 'feeling better'; and side-effects.

Most enquiries concerned side-effects and choice of prescribed therapy (see Table 2). Queries about therapy choice included a patient with schizophrenia wanting to know if risperidone was 'good'; a patient who had stopped taking antidepressants due to side-effects, wanting the pharmacist to recommend an antidepressant to suggest to his doctor; a patient wanting to know the difference in the mode of action between paroxetine, which she had previously been taking, and venlafaxine, which she was currently receiving. In cases where therapeutic judgement was questioned, the pharmacist either re-affirmed the prescriber's advice or recommended the patient discuss it further with the prescriber.

Patients usually volunteered their past medical history without prompting. One patient admitted attempted suicide with psychotropics, but was glad he had not been 'successful'. Another patient with depression was concerned about the amount of co-proxamol tablets and antidepressants he was accumulating because he frequently had suicidal ideation. He was advised to take the excess medication to a community pharmacy for disposal. This facility had been unknown to him. In addition, he learned only on seeing the community pharmacist that co-proxamol contained paracetamol. He had been taking other paracetamol-containing products concurrently.

\section{Evaluation of service}

The questionnaires for patients and staff were similar and comprised mainly closed questions with the option of giving more detailed answers.

\section{Patients}

Twenty-seven (82\%) patients responded. Some did not answer all the questions. Most patients gave more than one reason for using the advice service, indicating multiple unmet needs (see Table 3): Patients were mainly

\section{Table 2. Type of information requested $(n=33)$}

Enquiry category

Number of

individuals enquiring

Adverse effects

24

Therapy choice

17

Dose

Personal issue

Drug-drug interactions

Mental Health Act 1983/legislation

Dosage frequency

Identification of drug

Addiction

Miscellaneous
Table 3. Reasons for using the medication advice service $(n=25)$

Reason

Number of people giving reason (percentage of the total number of reasons; total $=65) n(\%)$

Concerned about adverse effects $16(25)$

Wanted independent advice

$14(22)$

Wanted reassurance

$12(18)$

Wanted to know purpose of drug(s) 8 (12)

Wanted to know how drug(s) worked 8 (12)

Wanted information on dosage $\quad 7$ (11)

frequencies

concerned about adverse effects and required independent advice. Twenty-four respondents were satisfied with the advice given by the community pharmacist. Only one respondent was not, explaining:

"Helpful, but not totally, because I wanted to know whether I should take the tablets recommended by the psychiatrist, but probably the pharmacist just wasn't able to give such an opinion".

This patient was wary of taking selective serotonin reuptake inhibitors suggested by his psychiatrist and preferred non-drug therapy. It seemed that the patient wanted his doubts supported. Obviously the community pharmacist was not in a position to do this.

All respondents found the service useful and all indicated the service was needed. Asked: "Has talking to the pharmacist helped you to understand your medicines better?" 24 respondents (92\%) said 'yes'. Reasons to support this included:

"(The pharmacist) provided useful information on medicines I'd been using for a long time without (me) being sure about sideeffects"

"(The pharmacist) gave practical information on paper (referring to UKPPG patient information leaflets) that was quite us eful. It is nice to know how medicines are affecting you".

Only one of the 24 respondents said they would not like a service like this to be available permanently, but no reason was given. Twenty-two (88\%; $n=25)$ said they would miss the service when it is withdrawn. There were no unfavourable comments made about the quality of advice.

\section{Staff}

Seven staff who were in regular, direct contact with the patients completed the questionnaire. All believed the patients found the service useful. All indicated they would like a service like this to be available all the time. Reasons included:

"There is a clear unmet need in this area. To have the service available... would be very useful".

"It gives confidence to service users on using appropriate medication".

Six said they thought members would miss this service if it was no longer available. 


\section{Comment}

The community pharmacist-run medication advice service was extensively used, the times allocated being fully utilised. Particularly noteworthy were the range of issues which worried patients, how much basic knowledge about their medication patients appeared to lack and the patients' appreciation of the community pharmacist's advice. It is also important to note that patients showed no reluctance to discuss their psychiatric problems with a community pharmacist. This perhaps justified the use of an independent pharmacist not directly involved in their treatment.

One important gap in patient knowledge concerned side-effects. Patients generally wanted to know how to manage them and whether they were serious.

Patients were told that the community pharmacist was not able to discuss therapy choice, but this was still the second most common enquiry made. This suggests that more patient involvement in the choice of drug treatment (the 'therapeutic alliance' (Working Party of the Royal Pharmaceutical Society of Great Britain, 1997)) may be needed in the prescribing process. Lack of an effective therapeutic alliance may result in 'nonconcordance', defined as ". . . failure of patient and prescriber to come to an understanding ..." (Working Party of the Royal Pharmaceutical Society of Great Britain, 1997).

In the Liverpool and Nottingham studies, antipsychotics (38\%) and antidepressants (31\%) were also the two most common drug types enquired about. Similarly, in a 1996 Mind report on the launch of the first year of its Yellow Card Scheme, of 473 reports, it was also found that antipsychotics and antidepressants were most commonly reported (Mind, 1996). This reflects their common use but also perhaps patients' concerns about their usage.

Staff considered the service useful to those who used and needed it. No unfavourable comments were reported directly by users of the service or to staff. This was encouraging, because the service evaluation forms were completed anonymously.

From this small study we were unable to draw any reliable conclusions about the patients' adherence to treatment. Bonnar et al (1969) showed that patients tended to overestimate their level of adherence when checked by objective means. Subjective assessments of adherence by patients are partly dependent on the patient's honesty. Corrigan et al (1990) stated that up to $80 \%$ of patients receiving antipsychotics fail to take their medicines regularly. Donoghue (1993) found that $56 \%$ of 81 psychiatric patients had at some time abandoned their medication, and in a Canadian study of 148 psychiatric patients, $66 \%$ of patients altered the dose or frequency of administration without the advice of the prescriber (Ruscher et al, 1997). In addition, patients may be adherent with some aspects of treatment and not with others. Moreover, there is no single, agreed definition of 'adherence'; it is a phenomenon extremely hard to define or quantify (Raynor, 1992).
The community pharmacist found some queries difficult to answer. In such cases, patients were asked to speak to their keyworker or psychiatrist (e.g. two patients receiving antipsychotics complaining of hypersalivation, and a patient receiving haloperidol injections complaining of dizziness (see Table 1)). In such cases, patients were also given the telephone number of the Maudsley Hospital-based medication helpline. This helpline is run by specialist psychiatric pharmacists who have expertise, experience and access to up-to-date references. Thus, due to the limited knowledge and skills of even a specially-trained community pharmacist, it would probably be desirable for specialist psychiatric hospital pharmacists to oversee a service such as this as it would be likely that they would need to be consulted from time to time when the community pharmacist is challenged with more difficult queries.

Based on the results of this limited pilot study involving only 33 consultations and using only a single community pharmacist, the following recommendations may be made:

(a) More research is required to evaluate such services. It would be useful to know the extent to which patients followed the pharmacists' advice, and measure patient outcome.

(b) Community pharmacists should receive postgraduate training in mental health prior to becoming involved and should be remunerated for the service.

(c) All consultations should be documented for subsequent evaluation and for legal and ethical reasons.

(d) An informal pharmacist referral system could be set up, whereby patients could be referred to a pharmacist by other mental health team workers, or onwards to them by the pharmacist.

(e) Specialist psychiatric pharmacists should oversee the service.

Several limitations to this pilot study should be recognised:

(a) Only one community pharmacist adviser was used. Characteristics of the community pharmacist (e.g. gender, age, prestige, expertise, ethnicity (Minichiello et al, 1990) may have influenced the results (a form of 'researcher bias' (Minichiello et al, 1990)).

(b) To improve validity it would be necessary to repeat the study in more centres.

\section{Acknowledgements}

The authors would like to thank the staff at the two participating mental health resource centres for their help with the organisation of this pilot study, in particular, Michael Quinn, Libby Agate, Koku Adomdza and Nega Alem and to all the users. We are also grateful to Rose Echlin (Commissioner for Mental Health Services, Bexley \& Greenwich Health Authority) for suggesting the service, and her support. Thank you to Shameem Mir and Barrat Luft at the Maudsley Hospital for the supply of UKPPG medication helpline cards and their interest in the service. original

papers 


\section{References}

ALDRIDGE, A., DINGWALL, R. \& WATSON, P. (1996) Evaluation of Two Pharmaceutical Care Programmes for People with Mental Health Problems in the Community. Discussion paper No. 96/03. Sheffield: Trent Institute for Health Services Research.

BONNAR, J., GOLDBERG, A. \& SMITH, J. A. (1969) Do pregnant women take their iron? Lancet, 1 457-458.

CORRIGAN, P.W., LIEBERMAN, R. P. \& ENGEL, J. D. (1990) From non-compliance to collaboration in the treatment of schizophrenia. Hospital and Community Psychiatry, 41, 1203-1211.
DONOGHUE, J. (1993) Problems with psychotropic medicines in the community. Pharmaceutical Journal, 251, 350-352.

- (1994) Report on a Pharmaceutical Facilitation Project in Community Mental Health Services, 1991-1903. Liverpool: Liverpool Family Health Services Authority.

MIND (1996) The Mental Health Charity. MIND's Yellow Card Scheme. Reporting the Adverse Effects of Psychiatric Drugs. London: Mind.

MINICHIELLO, V., ARONI, R., TIMEWELL, E., et al (1990) In-depth Interviewing. Researching People. Melbourne: Longman Cheshire.
NOTTINGHAMSHIRE FAMILY HEALTH SERVICES AUTHORITY (1994) Promoting the Health of the County. Nottinghamshire Pharmaceutical Facilitator Report. Aug 1991-July 1993 Nottingham: Nottinghamshire Health Authority

PSYCHIATRIC PHARMACY GROUP \& CHILTERN REGION OF THE ROYAL PHARMACEUTICAL SOCIETY OF GREAT BRITAIN (1997) Mental health in primary care. Pharmaceutical Journal, 258, 177.

RAYNOR, D. K. (1992) Patient compliance: the pharmacist's role. International Journal of Pharmaceutical Practice, 1, 126-135.

*Marilyn A. Ewan Postgraduate Research Student, Russell Greene Head of Pharmacy Practice Group, Department of Pharmacy, King's College, London, Franklin-Wilkins Building, 150 Stamford Street, London SE1 8WA

\section{Anorexia nervosa: service consumption and outcome of local patients in the Leicester service}

\author{
AIMS AND METHOD \\ A retrospective case note study pro- \\ vided data on the service consump- \\ tion and outcome of treatment for a \\ cohort of adult anorexia nervosa \\ sufferers treated in a specialised \\ secondary service.
}

\section{RESULTS}

A cohort of 106 patients was studied. Only just over a quarter were ever admitted. Of a subset of 78 patients, first seen before 1994, nearly onefifth failed to engage in treatment. Those who were admitted spent on average a total of 10 months in hospital, were in touch for four years and had over 100 therapy sessions. The majority who were treated solely as out-patients remained in touch with the service on average for over two years.

\section{CLINICAL IMPLICATIONS}

Services for anorexia nervosa sufferers need to plan for prolonged contact with their patients and high rates of service consumption.
Anorexia nervosa is a not uncommon disorder in adolescents and young adults (Hoek, 1991). It varies widely in severity, but is usually associated with considerable disruption, suffering and morbidity, both psychiatric and physical. Furthermore, it has one of the highest mortalities of any functional psychiatric disorder (Neilsen et al, 1998). It is often difficult to manage within general services and new specialist services are being created throughout the country (Palmer \& Treasure, 1999).

People suffering from anorexia nervosa are sometimes portrayed as 'difficult' patients. Certainly they are characteristically wary and have mixed feelings about treatment and change. The typical sufferer may hate the state in which she finds herself, but nevertheless she may be very fearful of what might happen were she to loosen the tenuous control which eating restraint seems to give her. The clinician who tries to help cannot simply apply treatments in an instrumental fashion. Treatment requires an adequate working alliance with the patient. The construction and maintenance of such an alliance may well be the most demanding part of the treatment process (Palmer, 1996).

Such difficulties have probably contributed to the relative dearth of good evidence about what treatments are and are not effective in this disorder. There are few randomised controlled trials and the results are difficult to generalise (Russell et al, 1987; Crisp et al, 1991) Systematic observational studies could provide another kind of evidence but these too are largely lacking as yet (Treasure \& Kordy, 1998). The worried clinician has to rely for advice mainly upon the accumulated experience and views of those who claim to know about these things. They do not always speak with one voice. Those who would plan rational services do not have much to go on.

The Leicester Eating Disorders Service is a specialist secondary service which takes adult patients (aged 16 years and above) from a defined catchment area of just under 1000 000. It accepts some referrals from afar, but 